\title{
Depression and Ambulatory Care Sensitive Hospitalizations among Medicare Beneficiaries with Chronic Physical Conditions
}

\author{
Rituparna Bhattacharya, $\mathbf{M S}^{1}$, Chan Shen, $\mathbf{P h D}^{2}$, and Usha Sambamoorthi, $\mathbf{P h D}^{1}$ \\ ${ }^{1}$ Department of Pharmaceutical Systems and Policy, School of Pharmacy, West Virginia \\ University, Morgantown, WV, USA \\ ${ }^{2}$ Department of Biostatistics, University of Texas, MD Anderson Cancer Center. Houston, Texas, \\ USA
}

\begin{abstract}
Objective-We examined the association between depression and hospitalizations for Ambulatory Care Sensitive Conditions (H-ACSC) among Medicare beneficiaries with chronic physical conditions.
\end{abstract}

\begin{abstract}
Methods-We used a retrospective longitudinal design using multiple years (2002-2009) of linked fee-for-service Medicare claims and survey data from Medicare Current Beneficiary Survey (MCBS) data to create six longitudinal panels. We followed individuals in each panel for a period of three years; first year served as the baseline and subsequent two years served as the follow-up. We measured depression, chronic physical conditions and other characteristics at baseline and examined H-ACSC at two follow-up. We identified chronic physical conditions from survey data and H-ACSC and depression from fee-for-service Medicare claims.. We analyzed unadjusted and adjusted relationships between depression and the risk of H-ACSC with chi-square tests and logistic regressions.
\end{abstract}

Results-Among all Medicare beneficiaries, 9.3\% had diagnosed depression. Medicare beneficiaries with depression had higher rates of any H-ACSC as compared to those without depression (13.6\% vs 7.7\%). Multivariable regression indicated that compared to those without depression, Medicare beneficiaries with depression were more likely to experience any H-ACSC.

Conclusions-Depression was associated with greater risk of H-ACSC, suggesting that healthcare quality measures may need to include depression as a risk-adjustment variable.

\section{Keywords}

preventable hospitalizations; depression; Medicare; Ambulatory Care Sensitive Conditions

\footnotetext{
(C) 2014 Elsevier Inc. All rights reserved.

Corresponding Author: Rituparna Bhattacharya, MS Department of Pharmaceutical Systems and Policy, School of Pharmacy, West Virginia University, Morgantown, WV 26506, USA (rbhattacharya@ hsc.wvu.edu).

Publisher's Disclaimer: This is a PDF file of an unedited manuscript that has been accepted for publication. As a service to our customers we are providing this early version of the manuscript. The manuscript will undergo copyediting, typesetting, and review of the resulting proof before it is published in its final citable form. Please note that during the production process errors may be discovered which could affect the content, and all legal disclaimers that apply to the journal pertain.
} 


\section{Introduction}

Individuals with co-occurring chronic physical and mental health conditions can be at high risk for poor quality of medical care[1]. A systematic review of 31 comparative studies, which examined the quality of general, cancer, cardiovascular, diabetes, and HIV care, concluded that, across disease states, the quality of care was poor among those with cooccurring chronic physical and mental health conditions compared to individuals with only chronic physical conditions [1]. When analyzed by type of healthcare utilization, a population-based longitudinal study from Australia found that among adults with diabetes, those with mental health conditions were $20 \%$ more likely to use inpatient services for diabetes-related complications compared to those without mental health conditions[2].

Although many hospitalizations among individuals with co-occurring chronic physical and mental health conditions can be due to patient-related complexities, some hospitalizations can be prevented. Preventable hospitalizations also known as hospitalizations for Ambulatory Care Sensitive Conditions (H-ACSC) are important measures of healthcare quality and has gained attention as a significant quality improvement issue [3]. H-ACSC accounted for more than $\$ 30$ billion [4] in annual health care spending in the United States (US). H-ACSC are hospitalizations, which could have been avoided by accessible and reasonably effective primary health care [5]. In the US, in a nationally representative sample of Medicare beneficiaries, individuals with multiple chronic physical conditions and mental illnesses were $60 \%$ more likely to experience H-ACSC as compared to individuals without multiple chronic conditions [6]. Among hospitalized patients in New York [7], individuals with mental illness had higher rates of H-ACSC compared to those without mental illnesses.

However, only a handful of studies have evaluated the association between specific mental illnesses such as depression and quality of care. According to the systematic review by Mitchell and colleagues [1], only five studies examined the association between depression and quality of care and four of these studies found inequalities in quality of care. In other studies that were not included in the review by Mitchell and colleagues, an association between depression and H-ACSC was found [8-10]. Among elderly Medicare beneficiaries with chronic heart failure and fee-for-coverage, depression was associated with $11 \%$ higher risk of H-ACSC [8]. Using 1999 data on 5\% random sample of fee-for-service Medicare beneficiaries with any one of the following eight conditions: coronary artery disease, diabetes mellitus, congestive heart failure, hypertension, prostate cancer, breast cancer, lung cancer, or colon cancer, it has been reported that elderly with depression were twice as likely as those without depression to have H-ACSC [9]. Among Veterans seen in five VA primary care sites, those with depression were more likely to have H-ACSC compared to Veterans without depression (Adjusted Odds Ratio (AOR):1.09; 95\% CI: 1.03, 1.17) [10]. Among individuals with diabetes, the presence of depression was associated with $41 \%$ and risk of $\mathrm{H}$ ACSC (Hazard Ratio: 1.41, $95 \%$ Confidence Interval [95 \% CI]: 1.15, 1.72) [11].

Although the above-mentioned studies have highlighted the negative impact of depression on H-ACSC, these studies are limited because they are either outdated $[8,9]$ or focused on a single disease $[8,11]$ or did not adjust for patient-level health factors such as perceived health status, functional status and other lifestyle risk factors such as perceived health status, 
functional status such as, smoking and obesity [9]. As H-ACSC rates have been increasing over time for some conditions [12], it is also important to examine the relationship between depression and H-ACSC using recent data. Therefore, the main objective of our study is to examine the association between depression and H-ACSC among Medicare beneficiaries with chronic physical conditions after controlling for independent variables (predisposing, enabling and need characteristics, personal health practices, and external environment), using recent data from a nationally representative sample of Medicare beneficiaries.

\section{Methods}

\section{Study Design}

We used a retrospective longitudinal panel study design using data from the Medicare Current Beneficiary Survey (MCBS).

\section{Data Source}

MCBS is an ongoing nationally representative sample of aged, disabled and institutionalized Medicare beneficiaries. The MCBS combines data collected from computer assisted personal interviews of the respondents with Medicare fee-for-service claims. The survey component collects data on a wide variety of variables such as health status, height and weight, functioning status, personal healthcare practices, activities of daily living, instrumental activities of daily living, living arrangement, history of medical conditions, the usual source of care, and preventive care. Survey information collected from the beneficiaries is integrated with provider services and covered charges data that are derived from Medicare claims, thus creating a unique dataset with components from both survey and administrative claims data.

The MCBS publishes two files annually, the MCBS Cost and Use file (MCBS-CU) and MCBS Access to Care (MCBS-AC) file. The MCBS-CU file links Medicare claims to survey-reported data MCBS-CU files goes through a process of reconciliation that combines information from survey respondents and Medicare administrative files.

The rotating panel design of the MCBS data comprises of four overlapping panels of Medicare Beneficiaries. Beneficiaries in each panel are interviewed three times a year, over a period of 4 years. Therefore, the MCBS data can be used to form a continuous profile of fee-for-service Medicare Beneficiaries' health care utilization data [13].

\section{Study Sample}

Our sample consisted of community-dwelling MCBS respondents enrolled in Medicare feefor-service and who reported any one of the following seven chronic physical conditions: arthritis, any cancer, diabetes, heart disease (myocardial infarction, coronary heart disease, and other heart conditions), hypertension, osteoporosis and respiratory diseases (chronic obstructive pulmonary disease -COPD, and asthma). We selected these seven conditions based on published studies establishing clinical burden (morbidity and mortality), economic burden and high prevalence [14-17] . We identified these conditions from the survey responses recorded in the health status and functioning files of the MCBS. 
We used the data from multiple years (2002-2009) of the MCBS to create six longitudinal panels: (i) 2002-04 (Panel 1); (ii) 2003-05 (Panel 2); (iii) 2004-06 (Panel 3); (iv) 2005-07 (Panel 4); (v) 2006-08 (Panel 5); (vi) 2007-09 (Panel 6). Therefore, we followed individuals in each panel for a period of three years. We used the first year of each panel as the baseline year and the subsequent two years were used as follow-up years. We measured depression, chronic physical conditions and other characteristics in the baseline year and examined $\mathrm{H}$ ACSC in the two follow-up years. The final sample size of 13,486 represented 2,378 beneficiaries in Panel 1; 2,419 in Panel 2; 2,272 in Panel 3; 2,239 in Panel 4; 2,125 in Panel 5; 2,053 in Panel 6.

\section{Dependent Variable: Hospitalization for Ambulatory Care Sensitive Conditions (H-ACSC)}

We identified the H-ACSC from fee-for-service Medicare claims during the follow-up period, using the Prevention Quality Indicators (PQI) software. This software was developed by investigators from Stanford University and University of California as a part of their contract with Agency of Healthcare Research and Quality (AHRQ). The PQI software module uses the International Classification of Diseases, 9th edition, clinical modification (ICD-9-CM) codes. PQIs were selected after conducting an extensive two phase literature reviews followed by evaluation based on face validity, precision testing, minimum bias, construct validity, fostering of quality improvement and applicability [18]. After identifying the individual PQIs, composite PQIs were generated to measure quality across multiple indicators and improve statistical power to detect differences in quality [19].

We adopted AHRQ's definition for over-all, acute and chronic composite PQIs [19] to measure any H-ACSC, acute condition and chronic disease related H-ACSC [19]. We identified individual H-ACSC during a calendar year and aggregated these at the person level. Using AHRQ's PQI software we identified individuals with any H-ACSC as those with hospitalizations for any of the following conditions: 1) diabetes short-term complications; 2) diabetes long-term complications; 3) chronic obstructive pulmonary disease (COPD); 4) hypertension; 5) congestive heart failure (CHF); 6) dehydration; 7) bacterial pneumonia; 8) urinary infections; 9) angina without a procedure; 10) uncontrolled diabetes; 11) adult asthma; and 12) lower extremity amputations among patients with diabetes. Acute condition related HACSC comprised of hospitalizations for dehydration, bacterial pneumonia and urinary infections. Chronic condition related H-ACSC consisted of hospitalizations for diabetes short-term complications, diabetes long-term complications, COPD, hypertension, CHF, angina without a procedure, uncontrolled diabetes, adult asthma and lower extremity amputations.

To examine the association between depression and specific disease-related H-ACSC we also identified H-ACSC related to cardio-vascular diseases (CHF, hypertension, angina without a procedure), diabetes (diabetes short-term complications, diabetes long-term complications; uncontrolled diabetes and lower extremity amputations among patients with diabetes), respiratory diseases (COPD and adult asthma) and infectious conditions (bacterial pneumonia and urinary infections). 


\section{Key Independent Variable: Presence or Absence of Depression}

We used primary and secondary ICD-9-CM diagnosis codes (296.2-major depressive disorder, single episode, and 296.3-major depressive disorder, recurrent episode, 300.4neurotic depression; 309.0-brief depressive reaction; 309.1-prolonged depressive reaction; 298.0-depressive type psychosis and 311-depressive disorder, not elsewhere classified) from fee-for-service Medicare claims at the baseline year to identify beneficiaries with diagnosed depression.

\section{Other Independent Variables}

We selected independent variables based on the modified version of the Andersen Behavioral Model (ABM) [20]. ABM incorporates both individual and contextual determinants of service utilization. These determinants include individuals' predisposition for using services (predisposing factors), factors that promote service utilization (enabling factors), and individual's need for services (need factors). The modified version of ABM also recognizes personal health practices and external environment as important factors affecting utilization of healthcare services.

Using the modified ABM, we measured all independent variables at the baseline year. These variables included predisposing characteristics (gender: women, men; race/ethnicity: White, African American, Latino, and other; age in years: less than 55 years, 56-64, 65-69, 70-74 and 75 or older), enabling characteristics (marital status: married, widowed, divorced/ separated, and other; education: less than high school, high school, some college and college; poverty status: less than $200 \%$, and greater than or equal to $200 \%$ of Federal Poverty Line and health insurance: Medicaid: yes,/no; private insurance: yes/no), need variables ( self-perceived general health: excellent, very good, good, fair, and poor and functional status: count of activities of daily living (ADL) limitations and any inpatient utilization), personal health practices (smoking status: current, past, never and body mass index (BMI): normal, overweight, obese and morbidly obese) and external healthcare environment (metro status: yes, no).

\section{Statistical Analysis}

We used chi-square tests to assess the statistical significance of unadjusted associations between depression and H-ACSC. We also conducted multivariable logistic regressions to examine the association between depression and H-ACSC after controlling for predisposing, enabling, need characteristics, external environment and personal health practices. We ran two logistic regression models for each dependent variable, model I controlled for all independent variables except baseline inpatient use and model II additionally adjusted for baseline inpatient use. We used c-statistics, which is same as the area under curve in logistic regression, to measure the goodness of model fit. We considered our model fit to be good if c-statistics was greater than 0.7 [21] We conducted all analyses using Statistical Analytic Software (SAS) version 9.3 and accounted for the complex survey structure of MCBS. Please note that while interpreting our results we have used risk and odds interchangeably whenever the prevalence rates of H-ACSC was less than 10\% [22]. 


\section{Results}

The study sample comprised of 13,486 persons ; majority were women (55.6\%), Whites $(81.1 \%)$, married $(55.3 \%)$, had income less than $200 \%$ of FPL $(50.6 \%)$ and resided in metropolitan area (71.9\%);16.3\% of study sample were dual Medicare and Medicaid users, $7.6 \%$ were non-elderly (less than 65 years of age); $17.3 \%$ had hospitalizations in baseline year.

Over-all 9.3\% of our study sample had depression. We observed significant subgroup differences in the presence of depression by predisposing (gender, age), enabling (marital status, poverty and insurance status and education), need (general health and functional status), and personal health practice (BMI and smoking status) characteristics (Table 1). For example, we observed higher rates of depression among women, $(11.7 \%)$, individuals with age $\leq 55$ (24\%), divorced or separated (14.9\%), with dual use of Medicare and Medicaid $(17.3 \%)$, who were morbidly obese (16.4\%) and current smokers $(14.6 \%)$ as compared to men $(6.2 \%)$, individuals 75 years or older (7.8\%), married (7.3\%), no dual use of Medicare and Medicaid (7.7\%), with normal BMI (8.8\%) and never smokers $(9.2 \%)$.

We found statistically significant differences in the rates of any H-ACSC, acute and chronic condition related H-ACSC by the presence of depression. Among all Medicare beneficiaries in our study sample, significantly higher percentage of individuals with depression had any $\mathrm{H}$-ACSC as compared to those without depression (13.6\% versus $7.7 \%)$. The rates were $6.0 \%$ versus $3.6 \%$ and $9.5 \%$ versus $4.8 \%$ ( $\mathrm{P}$-value $<0.0001$ ) for any acute condition and chronic disease related H-ACSC respectively. We observed similar results for H-ACSC related to cardio-vascular disease ( $4.8 \%$ versus $2.4 \%$ respiratory $(3.5 \%$ vs $1.5 \%)$ disease and infectious conditions ( $4.3 \%$ vs $2.9 \%$ ). We present the results in Table 2 . Only $1.3 \%$ of the study sample experienced diabetes related H-ACSC. Due to such small sample size the relative standard error (RSE) for this cell was 31.58; RSE > 30 are usually considered as unstable. Therefore, hereafter do not report the results of diabetes related H-ACSC.

Results from multivariable regressions revealed that without adjustment for any baseline inpatient use, Medicare beneficiaries with depression at baseline were more likely to experience any (adjusted odds ratios (AOR):1.53; 95\% confidence intervals (CI): 1.26,1.86; p-value <0.0001), acute condition related (AOR: 1.36; 95\% CI: 1.04, 1.77; p-value: 0.023), chronic disease related (AOR: 1.68; 95\% CI: 1.34, 2.12; p-value <0.0001), cardiovascular disease related (AOR: 1.71; 95\% CI: 1.24, 2.36; p-value: 0.001) and respiratory disease related (AOR: 1.72; When the models additionally adjusted for any baseline hospitalization use, we found that those with depression were $27 \%, 35 \%$ and $40 \%$ more likely to experience any (AOR: 1.27; 95\% CI: 1.04,1.55; p-value:0.017), any chronic disease (AOR: 1.35; 95\% CI: 1.07,1.72; p-value: 0.012) and cardio-vascular disease(AOR: 1.40; 95\% CI: 1.00,1.95; p-value 0.049) related H-ACSC respectively and multivariable results for any acute condition related or specific disease related H-ACSC were not statistically significant. The c-statistics for the logistic regression models ranged from 0.72 to 0.82 . 


\section{Relationship between other independent variables and any H-ACSC}

We found that, Medicare beneficiaries with certain predisposing (age: ages between 56-64, 65-69, 70-74 and 75 years or older vs 55 years or younger), enabling (marital status: widowed vs married) and need (self-perceived general health: very good, good, fair , poor vs excellent, functional status: those who 1-2 and 3-6 ADL limitations vs those with none) characteristics and personal health behaviors (smoking status: past, current smokers vs never smokers) had significantly greater odds of having H-ACSC. For example, current smokers and past smokers had 2.15 (AOR: 2.15; 95\% CI: 1.69, 2.75) and 1.40 (AOR: 1.40; 95\% CI: $1.18,1.63)$ times higher odds of any H- ACSC as compared to never smokers. Medicare beneficiaries with baseline hospital utilization had 171\% (AOR: 2.71; 95\% CI: 2.31, 3.17) increased risk of any H-ACSC. Details of these results can be requested from the primary author.

\section{Discussion}

In this paper we examined the association between depression and presence of H-ACSC among Medicare beneficiaries with chronic physical conditions such as arthritis, any cancer, diabetes, heart disease, hypertension, osteoporosis and respiratory conditions (COPD and asthma). In our study, Medicare beneficiaries with depression were at a greater risk of $\mathrm{H}$ ACSC compared to those without depression. This finding is consistent with existing literature that has documented disparities in quality of healthcare by mental health status in a variety of settings [1, 2, 6-10, 24-28]. Our study findings also have implications for the provision of primary care for those with depression. Collaborative care models which incorporate elements of mental health care into primary care [29] as well as behavioral health models which attempt to integrate primary care into mental health care (i.e. reverse integration) [30], have been shown to improve outcomes as well as quality of care, and the evidence is especially strong in case of depression [30]. As stated in the introduction, $\mathrm{H}$ ACSC can be prevented through timely provision of primary care. Therefore, among individuals with depression, co-management of depression and primary care thorough various processes such as assignment of therapists, engaging a care manager, consultations on an as needed basis and regularly scheduled case reviews and/or establishing formal protocols to update primary care providers on patient progress [30], may reduce the risk of H-ACSC . For example, integrated care delivery systems such as the Veterans Health Administration has shown co-location of mental health and primary care has been associated with improvements quality of care and outcomes for older and younger primary care patients with depression [31, 32].

Furthermore, the emerging healthcare delivery models may also aid in reducing in the risk of H-ACSC among individuals with chronic physical and mental health conditions such as depression. The Patient Protection and Affordable Care Act, passed in 2010, have incentives to promote integrated care through patient centered medical homes (PCMH) and Accountable Care Organizations (ACOs). Under the PCMH model, community mental health centers are among the providers that may qualify to be a health care home and may provide primary care services on site and therefore can meet the primary care and mental health care needs of individuals with mental illnesses [33]. Similarly, one of the ACO 
performance measure requires screening and subsequent follow-up treatment plan for depression; such explicit regulations may reduce the risk of H-ACSC among individuals with chronic physical conditions and depression [34]. However, recent evidence has suggested that treatment of depression with antidepressants may actually contribute to adverse health outcomes such as incident diabetes [35-38] and increased mortality among those with cardiovascular conditions $[39,40]$. Therefore, future research is needed to examine whether depression treatment can help in reducing the risk of H-ACSC among individuals with depression.

In addition to depression, other factors were also associated with H-ACSC. Notable among them are some pre-disposing and enabling factors such as age, social support (marital status) and personal health practices (smoking). We also observed that current smokers and past smokers were more likely to have H-ACSC as compared to non-smokers. Taken together, these findings have implications regarding expansion of risk adjustment variables for evaluating healthcare quality measures in emerging healthcare financing models. For example, the CMS has already implemented such risk adjustments for co-existing physical and mental health conditions such as major psychiatric disorders, depression, and substance use disorders in analyzing the risk for 30-day all-cause readmissions [41]. It has to be noted that, $\mathrm{H}-\mathrm{ACSC}$ is one of the 33 quality of care measures proposed by CMS. Rates of HACSC are being used to assess performance of ACOs. ACOs are held responsible for "bending the cost-curve" while providing high quality healthcare. ACOs that are participating in the Medicare Shared Savings Program (Shared Savings Program) [42] use expenditure patterns of Medicare beneficiaries in the past three years to set expenditure benchmarks. These benchmarks are used to establish savings and share the cost-reduction with the CMS. [43]. Given that many factors increase the risk of H-ACSC, it is important for these organizations to set the benchmark expenditures by expanding risk adjustment variables to include depression, smoking, and other factors that are beyond providers' control. Such risk-adjustments may be needed to guard against exclusion of high-at-risk subgroups in ACOs [44]. Additionally, baseline hospitalizations were also very significantly associated with H-ACSC. Individuals with prior inpatient use with in the past year may require additional surveillance should also be carefully monitored in primary care to avoid potentially preventable cases of H-ACSC.

Our study makes a significant contribution to the existing literature by examining the association between diagnosed depression, a commonly prevalent mental health condition, and an important marker of quality of care, namely H-ACSC $[45,46]$. The use of multiple years of nationally representative data of Medicare beneficiaries and the longitudinal study design strengthened the implications of the study. The unique structure of the MCBS data, where survey data linked with Medicare fee-for-service claims, enabled us to adjust for patient-level health factors (i.e. functional status, general health status and personal health practices), which are generally not available with claims data. As confirmed in longitudinal analysis, our results from cross-sectional analysis were also robust.

However, the results need to be interpreted in terms of study limitations. We were only able to capture diagnosed depression. Therefore, we may have under estimated rates of depression. Owing to the observational nature of our study design, our results only imply 
association and not causation. Our study sample was restricted to fee-for-service Medicare beneficiaries with a specific list of chronic conditions and therefore cannot be generalized to other Medicare beneficiaries. As compared to Medicare fee-for-service beneficiaries, those enrolled in Medicare Advantage plans, have been found to have a lower risk of H-ACSC [47]. Therefore, if the current study had included beneficiaries enrolled in Medicare Advantage plan, rates of H-ACSC may have been lower. However, given that two thirds of all Medicare beneficiaries are still under fee-for-service care, there is a need to monitor quality of care for these individuals. Additionally, the study variables that were based on self-reported data may have been subjected to recall-bias. Variables identified from fee-forservice claims using ICD-9-CM diagnosis codes may have suffered from coding errors such as under coding and over coding. For example, depression diagnosis was identified from Medicare fee-for-service claims; such claims based diagnosis of depression has been known to suffer from poor sensitivity resulting from underestimation of depression prevalence [48].

\section{Conclusions}

Our study results indicated that Medicare beneficiaries with depression are at higher risk for H-ACSC. Future research needs to examine whether routine screening of depression to detect depression early and treating depression once detected can reduce the risk of $\mathrm{H}$ ACSC. Our study findings highlight the need to include depression in risk-adjustment of healthcare quality measures and reinforce the need for integrated primary and mental healthcare and the role of emerging healthcare delivery models in reducing the risk of $\mathrm{H}$ -

ACSC.

\section{Acknowledgments}

The project described was supported by the National Institute Of General Medical Sciences, U54GM104942. The content is solely the responsibility of the authors and does not necessarily represent the official views of the NIH."

\section{REFERENCES}

1. Mitchell AJ, Malone D, Doebbeling CC. Quality of medical care for people with and without comorbid mental illness and substance misuse: systematic review of comparative studies. The British journal of psychiatry : the journal of mental science. 2009; 194:491-9. [PubMed: 19478286]

2. Mai Q, Holman CD, Sanfilippo FM, Emery JD, Preen DB. Mental illness related disparities in diabetes prevalence, quality of care and outcomes: a population-based longitudinal study. BMC medicine. 2011; 9:118. [PubMed: 22044777]

3. Kruzikas DTJH, Remus D, Barrett ML, Coffey RM, Andrews R. Preventable hospitalizations: A window into primary and PreventiveCare,2000. Agency for Healthcare Research and Quality. 2004

4. Torio, CMEA.; Andrews, RM. [December 12, 2013] Trends in Potentially Preventable Hospital Admissions among Adults and Children, 2005-2010.. Agency of Health Care Research and Quality. 2013. HCUP Statistical Brief \#151. Avaiable at: http://www.hcup-us.ahrq.gov/reports/statbriefs/ sb151.pdf.

5. Hossain MM, Laditka JN. Using hospitalization for ambulatory care sensitive conditions to measure access to primary health care: an application of spatial structural equation modeling. International journal of health geographics. 2009; 8:51. [PubMed: 19715587]

6. Ajmera M, Wilkins TL, Findley PA, Sambamoorthi U. Multimorbidity, Mental Illness, and Quality of Care: Preventable Hospitalizations among Medicare Beneficiaries. International journal of family medicine. 2012; 2012:823294. [PubMed: 23320168] 
7. Li Y, Glance LG, Cai X, Mukamel DB. Mental illness and hospitalization for ambulatory care sensitive medical conditions. Medical care. 2008; 46:1249-56. [PubMed: 19300315]

8. Braunstein JB, Anderson GF, Gerstenblith G, Weller W, Niefeld M, Herbert R, et al. Noncardiac comorbidity increases preventable hospitalizations and mortality among Medicare beneficiaries with chronic heart failure. Journal of the American College of Cardiology. 2003; 42:1226-33. [PubMed: 14522486]

9. Himelhoch S, Weller WE, Wu AW, Anderson GF, Cooper LA. Chronic medical illness, depression, and use of acute medical services among Medicare beneficiaries. Medical care. 2004; 42:512-21. [PubMed: 15167319]

10. Yoon J, Yano EM, Altman L, Cordasco KM, Stockdale SE, Chow A, et al. Reducing costs of acute care for ambulatory care-sensitive medical conditions: the central roles of comorbid mental illness. Medical care. 2012; 50:705-13. [PubMed: 22437618]

11. Davydow DS, Katon WJ, Lin EH, Ciechanowski P, Ludman E, Oliver M, et al. Depression and risk of hospitalizations for ambulatory care-sensitive conditions in patients with diabetes. Journal of general internal medicine. 2013; 28:921-9. [PubMed: 23325384]

12. [3 Fenruary, 2014] The Commonwealth Fund.Hospitalizations for Ambulatory Care Sensitive Conditions. Available at: http://www.commonwealthfund.org/Performance-Snapshots/Overuse-ofHealth-Care-Services/Hospitalizations-for-Ambulatory-Care--8211-Sensitive-Conditions.aspx.

13. Center for Medicare \& Medicaid services. [Deecember 12, 2013] Technical documentation for the medicare current beneficiary survey. Centers for Medicare and Medicaid Services. 2003. Available at: http://www.cms.gov/Research-Statistics-Data-and-Systems/Research/MCBS/downloads/ HHC2003appendixA.pdf.

14. Soni, A. [December 12, 2013] The Five Most Costly Conditions, 2000 and 2004: Estimates for the U.S. Civilian Noninstitutionalized Population.. Agency for Healthcare Research and Quality. 2007. Statistical Brief \#167. Avaiable at http://meps.ahrq.gov/mepsweb/data_files/publications/ st167/stat167.pdf.

15. Ostbye T, Yarnall KS, Krause KM, Pollak KI, Gradison M, Michener JL. Is there time for management of patients with chronic diseases in primary care? Annals of family medicine. 2005; 3:209-14. [PubMed: 15928223]

16. Roehrig C, Miller G, Lake C, Bryant J. National health spending by medical condition, 1996-2005. Health affairs. 2009; 28:w358-67. [PubMed: 19240056]

17. Agency for Healthcare Research and Quality, Department of Health and Human Services. Medical Expenditure Panel Survey (MEPS) HC-113: 2007 Full Year Consolidated Data File. AHQR; Rockville, Md, USA: 2009.

18. [December 12, 2013] Prevention Quality Indicators Resources: AHRQ QI Development.. Agency for Healthcare Research and Quality. 2011. Available at: http://www.qualityindicators.ahrq.gov/ Modules/pqi_resources.aspx.

19. Agency for Healthcare Research and Quality. Quality Indicator User Guide: Prevention Quality Indicators (PQI) Composite Measures. AHRQ; Rockville, Md, USA: 2012. Report No.: Version 4.4

20. Andersen RM. Revisiting the behavioral model and access to medical care: does it matter? Journal of health and social behavior. 1995; 36:1-10. [PubMed: 7738325]

21. Hosmer, DW., Jr; Lemeshow, S. Applied logistic regression. John Wiley \& Sons; 2004.

22. Davies HT, Crombie IK, Tavakoli M. When can odds ratios mislead? Bmj. 1998; 316:989-91. [PubMed: 9550961]

23. Stranges, E.; Stocks, C. [December 12, 2013] Potentially Preventable Hospitalizations for Acute and Chronic Conditions. Agency for Healthcare Research and Quality 2010. 2008. HCUP Statistical Brief \#99. Avaiable at: http://www.hcup-us.ahrq.gov/reports/statbriefs/sb99.jsp.

24. Mai Q, Holman CD, Sanfilippo FM, Emery JD. The impact of mental illness on potentially preventable hospitalisations: a population-based cohort study. BMC psychiatry. 2011; 11:163. [PubMed: 21985082]

25. Lawrence D, Kisely S. Inequalities in healthcare provision for people with severe mental illness. Journal of psychopharmacology. 2010; 24:61-8. [PubMed: 20923921] 
26. Frayne SM, Halanych JH, Miller DR, Wang F, Lin H, Pogach L, et al. Disparities in diabetes care: impact of mental illness. Archives of internal medicine. 2005; 165:2631-8. [PubMed: 16344421]

27. Desai MM, Rosenheck RA, Druss BG, Perlin JB. Mental disorders and quality of diabetes care in the veterans health administration. The American journal of psychiatry. 2002; 159:1584-90. [PubMed: 12202281]

28. Becker MA, Boaz TL, Andel R, Gum AM, Papadopoulos AS. Predictors of preventable nursing home hospitalizations: the role of mental disorders and dementia. The American journal of geriatric psychiatry : official journal of the American Association for Geriatric Psychiatry. 2010; 18:475-82. [PubMed: 21217558]

29. Hunkeler EM, Katon W, Tang L, Williams JW Jr. Kroenke K, Lin EH, et al. Long term outcomes from the IMPACT randomised trial for depressed elderly patients in primary care. Bmj. 2006; 332:259-63. [PubMed: 16428253]

30. Butler M, Kane RL, McAlpine D, Kathol RG, Fu SS, Hagedorn H, Wilt TJ. Integration of mental health/substance abuse and primary care. 2008

31. Felker BL, Chaney E, Rubenstein LV, Bonner LM, Yano EM, Parker LE, et al. Developing effective collaboration between primary care and mental health providers. Primary care companion to the Journal of clinical psychiatry. 2006; 8:12-6.

32. Zeiss AM, Karlin BE. Integrating mental health and primary care services in the Department of Veterans Affairs health care system. Journal of clinical psychology in medical settings. 2008; 15:73-8. [PubMed: 19104957]

33. David, L. [December 12, 2013] How will health reform help people with mental illnesses? An analysis of the Affordable Care Act passed by Congress in 2010 and how it will affect people with psychiatric disabilities.. Bazelon Center for Mental Health Law. 2009. Avaiable at: http:// csmh.umaryland.edu/Toolbar/Toolbardocs/Bazelonhealthreform.pdf.

34. O'Donnell AN, Williams BC, Eisenberg D, Kilbourne AM. Mental health in ACOs: missed opportunities and low-hanging fruit. The American journal of managed care. 2013; 19:180-4. [PubMed: 23544760]

35. Andersohn F, Schade R, Suissa S, Garbe E. Long-term use of antidepressants for depressive disorders and the risk of diabetes mellitus. The American journal of psychiatry. 2009; 166:591-8. [PubMed: 19339356]

36. Atlantis E, Browning C, Sims J, Kendig H. Diabetes incidence associated with depression and antidepressants in the Melbourne Longitudinal Studies on Healthy Ageing (MELSHA). International journal of geriatric psychiatry. 2010; 25:688-96. [PubMed: 19806604]

37. Jindal RD. Long-term antidepressant use and risk for diabetes: cause for concern and optimism. The American journal of psychiatry. 2009; 166:1065-6. author reply 1066. [PubMed: 19723798]

38. Rubin RR, Ma Y, Marrero DG, Peyrot M, Barrett-Connor EL, Kahn SE, et al. Elevated depression symptoms, antidepressant medicine use, and risk of developing diabetes during the diabetes prevention program. Diabetes care. 2008; 31:420-6. [PubMed: 18071002]

39. Monte S, Macchia A, Romero M, D'Ettorre A, Giuliani R, Tognoni G. Antidepressants and cardiovascular outcomes in patients without known cardiovascular risk. European journal of clinical pharmacology. 2009; 65:1131-8. [PubMed: 19597805]

40. Smoller JW, Allison M, Cochrane BB, Curb JD, Perlis RH, Robinson JG, et al. Antidepressant use and risk of incident cardiovascular morbidity and mortality among postmenopausal women in the Women's Health Initiative study. Archives of internal medicine. 2009; 169:2128-39. [PubMed: 20008698]

41. Centers for Medicare and Medicaid Services. [26 April 2014] Readmissions Reduction Program. Available from: http://www.cms.gov/Medicare/Medicare-Fee-for-Service-Payment/ AcuteInpatientPPS/Readmissions-Reduction-Program.html.

42. Centers for Medicare and Medicaid Services. [26 April, 2014] Medicare Shared Savings Program Quality Measure Benchmarks for the 2014 and 2015 Reporting Years. Available at: http:// www.cms.gov/Medicare/Medicare-Fee-for-Service-Payment/sharedsavingsprogram/Downloads/ MSSP-QM-Benchmarks.pdf. 
43. The Commonwealth Fund. [26 April, 2014] The Final Rule for the Medicare Shared Savings Program. http://www.commonwealthfund.org/ /media/Files/Publications/Other/2011/ ZezzasummaryfinalruleM edicaresharedsavingsv2\%202.pdf\%29.

44. Pollack CE, Armstrong K. Accountable care organizations and health care disparities. JAMA : the journal of the American Medical Association. 2011; 305:1706-7. [PubMed: 21521853]

45. McCall NT, Parks P, Smith K, Pope G, Griggs M. The prevalence of major depression or dysthymia among aged Medicare Fee-for-Service beneficiaries. International journal of geriatric psychiatry. 2002; 17:557-65. [PubMed: 12112180]

46. Centers for Medicare and Medicaid Services. Chronic Conditions among Medicare Beneficiaries, Chartbook, 2012 Edition. Centers for Medicare and Medicaid Services; 2012. Avaiable at: http:// www.cms.gov/Research-Statistics-Data-and-Systems/Statistics-Trends-and-Reports/ChronicConditions/Downloads/2012Chartbook.pdf. [December 12, 2013]

47. Basu J. Medicare managed care and primary care quality: examining racial/ethnic effects across states. Health care management science. 2012; 15:15-28. [PubMed: 21892596]

48. Noyes K, Liu H, Lyness JM, Friedman B. Medicare beneficiaries with depression: comparing diagnoses in claims data with the results of screening. Psychiatric services. 2011; 62:1159-66. [PubMed: 21969642] 
Table 1

Sample Description of Medicare Beneficiaries by Depression Medicare Current Beneficiary Survey 2002-2009

\begin{tabular}{|c|c|c|c|c|c|}
\hline & \multicolumn{2}{|c|}{ Depression } & \multicolumn{2}{|c|}{ No Depression } & \multirow[b]{2}{*}{ Sig } \\
\hline & $\mathbf{N}$ & $\mathrm{Wt} \%$ & $\mathbf{N}$ & $\mathrm{Wt} \%$ & \\
\hline All & 1,303 & 9.3 & 12,183 & 90.7 & \\
\hline Gender & & & & & $* * *$ \\
\hline Female & 897 & 11.7 & 6,539 & 88.3 & \\
\hline Male & 406 & 6.2 & 5,644 & 93.8 & \\
\hline \multicolumn{6}{|l|}{ Race/Ethnicity } \\
\hline White & 1,047 & 9.3 & 9,822 & 90.7 & \\
\hline African American & 96 & 7.9 & 1,090 & 92.1 & \\
\hline Latino & 97 & 10.7 & 714 & 89.3 & \\
\hline Others & 61 & 10.0 & 539 & 90.0 & \\
\hline Age & & & & & $* * *$ \\
\hline Less Than or Equal To 55 & 322 & 24.0 & 1,107 & 76.0 & \\
\hline $56-64$ & 128 & 16.8 & 602 & 83.2 & \\
\hline $65-69$ & 202 & 6.7 & 2,573 & 93.3 & \\
\hline $70-74$ & 156 & 6.9 & 2,082 & 93.1 & \\
\hline Greater Than 75 & 495 & 7.8 & 5,819 & 92.2 & \\
\hline Marital Status & & & & & $* * *$ \\
\hline Married & 518 & 7.3 & 6,500 & 92.7 & \\
\hline Widowed & 410 & 10.3 & 3,600 & 89.7 & \\
\hline Divorced/Separated & 241 & 14.9 & 1,291 & 85.1 & \\
\hline Other & 133 & 11.9 & 790 & 88.1 & \\
\hline \multicolumn{6}{|l|}{ Metropolitan Area } \\
\hline Yes & 893 & 9.2 & 8,397 & 90.8 & \\
\hline No & 410 & 9.4 & 3,784 & 90.6 & \\
\hline Education & & & & & $* * *$ \\
\hline Less Than or Equal To High School & 402 & 10.1 & 3,405 & 89.9 & \\
\hline High School & 506 & 9.5 & 4,572 & 90.5 & \\
\hline Some coll & 208 & 10.6 & 1,709 & 89.4 & \\
\hline College & 180 & 6.7 & 2,456 & 93.3 & \\
\hline Poverty Status & & & & & $* * *$ \\
\hline Greater Than or Equal To $200 \%$ & 441 & 7.1 & 5,766 & 92.9 & \\
\hline Less Than $200 \%$ & 862 & 11.4 & 6,417 & 88.6 & \\
\hline Medicaid & & & & & $* * *$ \\
\hline Yes & 449 & 17.3 & 2,123 & 82.7 & \\
\hline No & 854 & 7.7 & 10,060 & 92.3 & \\
\hline Private Insurance & & & & & $* * *$ \\
\hline
\end{tabular}




\begin{tabular}{|c|c|c|c|c|c|}
\hline & \multicolumn{2}{|c|}{ Depression } & \multicolumn{2}{|c|}{ No Depression } & \multirow[b]{2}{*}{ Sig } \\
\hline & $\mathbf{N}$ & $\mathrm{Wt} \%$ & $\mathbf{N}$ & $\mathrm{Wt} \%$ & \\
\hline Yes & 750 & 7.9 & 8,588 & 92.1 & \\
\hline No & 553 & 12.7 & 3,595 & 87.3 & \\
\hline General Health Status & & & & & $* * *$ \\
\hline Excellent & 79 & 4.4 & 1,765 & 95.6 & \\
\hline Very good & 204 & 5.4 & 3,356 & 94.6 & \\
\hline Good & 399 & 8.8 & 4,025 & 91.2 & \\
\hline Fair & 368 & 14.0 & 2,174 & 86.0 & \\
\hline Poor & 248 & 23.0 & 808 & 77.0 & \\
\hline Activities of Daily Living (ADL) & & & & & $* * *$ \\
\hline None & 732 & 7.5 & 8,630 & 92.5 & \\
\hline $1-2$ & 359 & 12.1 & 2,575 & 87.9 & \\
\hline 3-6 & 208 & 18.1 & 957 & 81.9 & \\
\hline Body Mass Index & & & & & $* * *$ \\
\hline Underweight & 42 & 13.9 & 245 & 86.1 & \\
\hline Normal & 407 & 8.8 & 4,015 & 91.2 & \\
\hline Oveweight & 418 & 8.2 & 4,662 & 91.8 & \\
\hline Obese & 333 & 9.9 & 2,757 & 90.1 & \\
\hline Morbidly Obese & 83 & 16.4 & 385 & 83.6 & \\
\hline \multicolumn{6}{|l|}{ Smoking Status } \\
\hline Current smoker & 283 & 14.6 & 1,553 & 85.4 & $* * *$ \\
\hline Past smoker & 491 & 7.7 & 5,632 & 92.3 & \\
\hline Never smoked & 528 & 9.2 & 4,979 & 90.8 & \\
\hline \multicolumn{6}{|l|}{ Baseline Hospitalizations } \\
\hline Yes & 470 & 18.6 & 2,027 & 81.4 & \\
\hline No & 833 & 7.3 & 10,156 & 92.7 & \\
\hline
\end{tabular}

Note: Based on a sample of 13,486 community dwelling Medicare beneficiaries who were followed for 3 years, were first interviewed in 2002, $2003,2004,2005,2006$ or 2007, enrolled in feefor-service program and had at least one chronic physical condition (arthritis, cancer, diabetes, heart disease (myocardial infarction, coronary heart disease, and other heart conditions), hypertension, respiratory diseases (chronic obstructive pulmonary disease - COPD, and asthma), and osteoporosis). Asterisks represent statistical significance between women and men based on Chisquare tests

Sig: significance, $\mathrm{Wt} \%$ : weighted percentage **** $\mathrm{p}<0.001$ 
Table 2

Hospitalizations for Ambulatory Care Sensitive Conditions (H-ACSC) of Medicare Beneficiaries by Depression Medicare Current Beneficiary Survey 2002-2009

\begin{tabular}{|c|c|c|c|c|c|c|c|}
\hline \multicolumn{8}{|c|}{ Over-all Sample } \\
\hline & \multicolumn{2}{|r|}{ ALL } & \multicolumn{2}{|c|}{ Depression } & \multicolumn{3}{|c|}{ No Depression } \\
\hline & \multicolumn{2}{|c|}{$\mathrm{N}=13,486$} & \multicolumn{2}{|c|}{$\mathrm{N}=1, \mathbf{3 0 3}$} & \multicolumn{3}{|c|}{$N=12,183$} \\
\hline & $\mathbf{N}$ & Wt $\%$ & $\mathbf{N}$ & $\mathbf{W t} \%$ & $\mathbf{N}$ & Wt $\%$ & Sig \\
\hline Any H-ACSC & 1,200 & 8.2 & 175 & 13.6 & 1,025 & 7.7 & $* * *$ \\
\hline Any Acute Condition Related H-ACSC & 572 & 3.8 & 81 & 6.0 & 491 & 3.6 & $* * *$ \\
\hline Any Chronic Disease Related H-ACSC & 754 & 5.2 & 120 & 9.5 & 634 & 4.8 & $* * *$ \\
\hline \multicolumn{8}{|l|}{ Specific Disease Related H-ACSC } \\
\hline Diabetes & 105 & 0.7 & & & \multicolumn{3}{|c|}{ Not Reported ${ }^{\#}$} \\
\hline Cardio-vascular Diseases & 390 & 2.7 & 60 & 4.8 & 330 & 2.4 & $* * *$ \\
\hline Respiratory Diseases & 239 & 1.7 & 44 & 3.5 & 195 & 1.5 & $* * *$ \\
\hline Infectious Conditions & 441 & 3.0 & 57 & 4.3 & 384 & 2.9 & $* *$ \\
\hline
\end{tabular}

Note: Based on a sample of 13,486 community dwelling Medicare beneficiaries who were followed for 3 years, were first interviewed in 2002, 2003, 2004, 2005, 2006 or 2007, enrolled in fee-for-service program and had at least one chronic physical condition (arthritis, cancer, diabetes, heart disease (myocardial infarction, coronary heart disease, and other heart conditions), hypertension, respiratory diseases (chronic obstructive pulmonary disease - COPD, and asthma), and osteoporosis). H-ACSC included hospitalizations for: diabetes short-term complications, diabetes long-term complications, chronic obstructive pulmonary disease, hypertension, congestive heart failure, dehydration, bacterial pneumonia, urinary infections, angina without a procedure, uncontrolled diabetes, adult asthma and lower extremity amputations among patients with diabetes.

Asterisks represent statistical significance based on chi-square statistics.

$0.01<\mathrm{p} \leq 0.05$

$* * *$

$\mathrm{p} \$ 0.001$

**

$0.001<\mathrm{p} \leq 0.01$

$\not$

$¥$ Results are unstable due to low sample size and relative standard error > 30. Results not reported Wt $\%$ : Weighted percentage; Sig: significance; COPD: Chronic Obstructive Pulmonary Disease 
Table 3

Adjusted Odds Ratios (AOR) and 95\% Confidence Interval (CI) from Logistic Regression for Estimating the Association between Depression and Hospitalizations for Ambulatory Care Sensitive Condition (H-ACSC) Medicare Current Beneficiary Survey 2002-2009

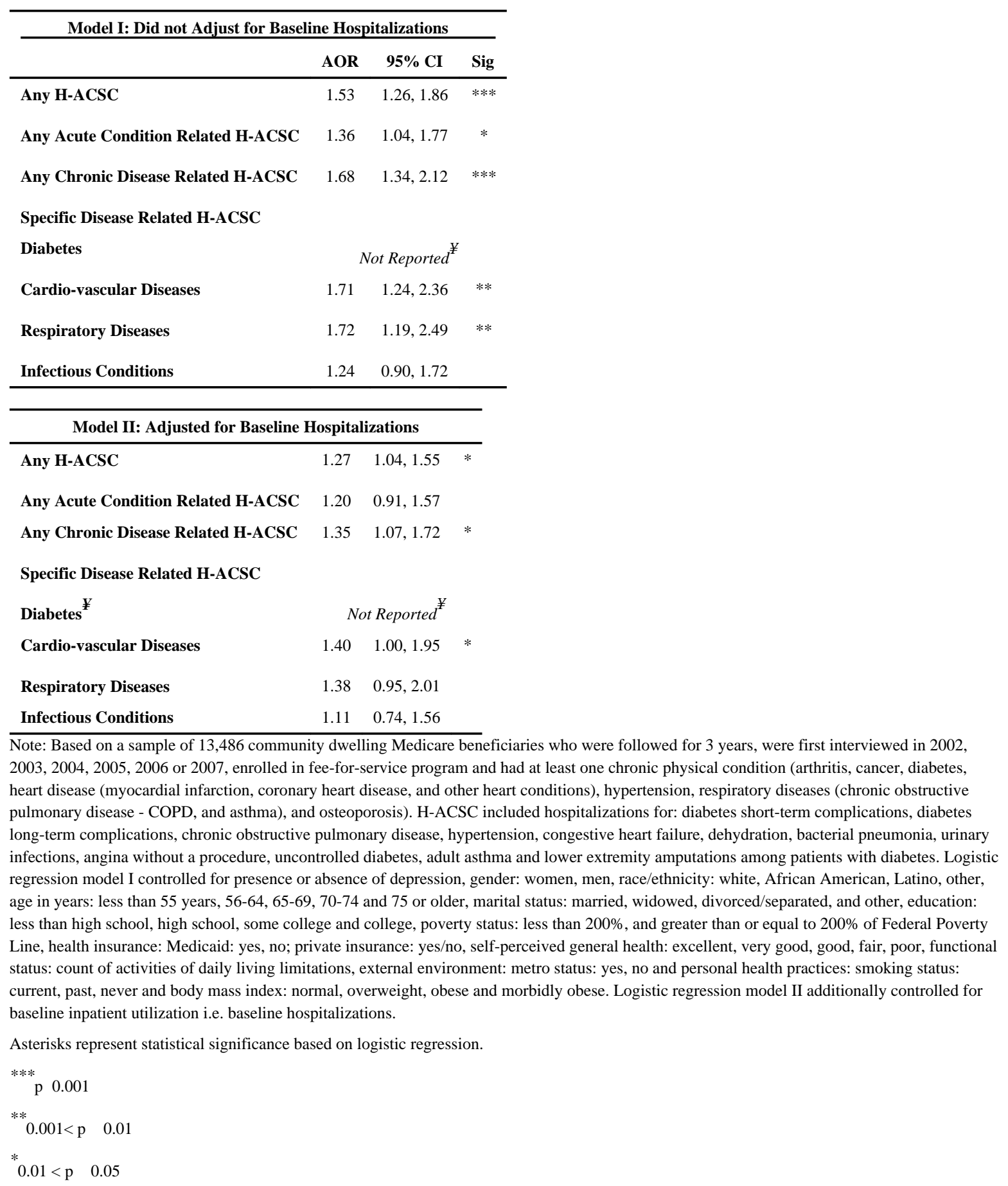


${ }^{¥}$ Results are unstable due to low sample size and relative standard error < 30. Results not reported Sig: significance; COPD: Chronic Obstructive Pulmonary Disease 